\title{
Current health status and its risk factors of (a) CrossMark the Tsarang villagers living at high altitude in the Mustang district of Nepal
}

Sweta Koirala 1,2,3, Masayuki Nakano ${ }^{1,4^{*}}$ (D) Hiroaki Arima ${ }^{1,3}$, Shouhei Takeuchi ${ }^{5}$, Tomo Ichikawa ${ }^{1,6}$, Takayuki Nishimura ${ }^{7}$, Hiromu Ito ${ }^{1,8,11}$, Basu Dev Pandey ${ }^{9,10}$, Kishor Pandey 9,12 , Takayuki Wada ${ }^{1,13}$ and Taro Yamamoto ${ }^{1,2,3}$

\begin{abstract}
Background: Epidemiology of noncommunicable diseases (NCDs) such as obesity and diabetes mellitus (DM) are influenced by multiple hosts and environmental factors. This study aims to investigate the prevalence of NCDs and determine their risk factors among the adults residing in an isolated village situated at a rural highland of Nepal.

Methods: A cross-sectional survey was conducted in a village located at $3570 \mathrm{~m}$. Each 188 randomly selected participants of age $\geq 18$ years old answered a questionnaire and took a full physical exam that included biomedical measurements of glycosylated hemoglobin (HbA1c).

Results: The prevalence of intermediate hyperglycemia and DM was $31.6 \%$ and $4.6 \%$ respectively, and the prevalence of hypoxemia $\left(\mathrm{SpO}_{2}<90 \%\right.$ ) was $27.1 \%$. A multiple logistic regression analysis for factors for the prevalence of glucose intolerance $(\mathrm{HbA} 1 \mathrm{c} \geq 6 \%$ ) revealed older age (odds ratio [OR] 1.11, 95\% confidence interval [Cl] 1.06-1.16, for every 1 year increase) and $\mathrm{SpO}_{2}$ (OR for hypoxemia 3.58, 95\% Cl 1.20-10.68, vs $\mathrm{SpO}_{2} \geq 90 \%$ ).
\end{abstract}

Conclusions: Tibetan highlanders in the remote mountainous Mustang valley of Nepal have high prevalence of impaired glucose metabolism which could be related to hypoxemia imposed by the hypoxic conditions of high altitude living.

Keywords: High altitude, Health status, Noncommunicable diseases, Cross-sectional studies, Risk factors

\section{Background}

Low- and middle-income countries are facing with burdens of two major public health concerns, communicable and noncommunicable diseases (NCDs). While the number of patients with communicable diseases is gradually falling throughout the world, NCDs including cardiovascular diseases, cancers, and diabetes are growing rapidly and are expected to further expand throughout the world $[1,2]$. Source of death in the low-income countries will predominantly be the result of NCDs in near future [3]. NCDs like diabetes mellitus (DM), obesity, and hypertension (HT) are one of the most serious public health concerns resulting in severe healthcare burdens throughout the world $[1,4]$. Each year, NCDs account for 40 million deaths

\footnotetext{
* Correspondence: manakano@nagasaki-u.ac.jp

${ }^{1}$ Department of International Health, Institute of Tropical Medicine, Nagasaki

University, 1-12-4 Sakamoto, Nagasaki 852-8523, Japan

${ }^{4}$ Department of Bacteriology, Institute of Tropical Medicine, Nagasaki

University, 1-12-4 Sakamoto, Nagasaki 852-8523, Japan

Full list of author information is available at the end of the article
}

globally, and $80 \%$ of the premature deaths due to NCDs occur in low- and middle-income countries [5].

In Nepal, a World Bank defined low-income country, a nationwide survey on NCDs revealed that multifactorial elements were involved in the growing burden of NCDs as an emerging public health concern [6]. The World Health Organization (WHO) have reported that the proportion of deaths related to NCDs has risen from $51 \%$ in 2010 to $60 \%$ in 2014, indicating that NCDs are one of the most important health issues [4, 7]. Because of the increasing trend in NCDs, the Nepalese government established the multi-sectorial action plan for the prevention and control of NCDs [8]. In order to achieve this plan, it requires understanding about current health status including the prevalence of NCDs and their risk factors of the population at the national level. Unfortunately, Nepalese population-based studies on incidence and prevalence of NCDs and their risk factors are limited $[9,10]$.

(c) The Author(s). 2018 Open Access This article is distributed under the terms of the Creative Commons Attribution 4.0 International License (http://creativecommons.org/licenses/by/4.0/), which permits unrestricted use, distribution, and reproduction in any medium, provided you give appropriate credit to the original author(s) and the source, provide a link to the Creative Commons license, and indicate if changes were made. The Creative Commons Public Domain Dedication waiver (http://creativecommons.org/publicdomain/zero/1.0/) applies to the data made available in this article, unless otherwise stated. 
Nepal has a large geographical diversity from lowland in the south to over $8000 \mathrm{~m}$ in mountainous areas in the north. Almost 2 million people or $6.7 \%$ of the population of Nepal live permanently in mountainous area [11]. Living at high altitudes involves long-term adaptation to harsh environment and altitude induced hypoxia. Residents living at altitude must deal with severe environmental and physiological stress and may be more likely to exhibit adaptive responses such as energy production, ventilation, and oxygen diffusion in blood stream [12]. Tsarang village (3570 $\mathrm{m}$ above sea level) is in an economically impoverished, remote mountainous region in Mustang district neighboring the Tibetan area of China and had long been isolated from other parts of Nepal. The restricted sacred kingdom of Mustang commenced tourism only in 1992. Because of its history, it is the most preserved region of the world and belongs to the national conservation area. Locals are adapted to the harsh environmental conditions; the economy is agro-pastoralism, and Tsarang village in Nepal has Tibetan population. However, it is facing recent globalization with access to road and trekking tourism industry. Previous studies have noted that high altitude has effects on the development NCDs including obesity and $\mathrm{HT}$, suggesting that the prevalence of NCDs and risk factors for development of diseases at high altitude might be different from lowland areas [13-15]. Prevalence of obesity, specifically central obesity, is common among Tibetans. Sherpa et al. states that while there is a significant decrease in body mass index (BMI) with increasing level of altitude, there is no corresponding decrease in waist circumference (WC), suggesting that people living at high altitude have a higher prevalence of central obesity as compared to generalized total body fat measured by BMI [16]. Research shows obesity and being overweight occurred less in mountainous areas $(9 \%)$ than in hills $(26 \%)$ or nationwide $(21 \%)$ in Nepal [6].

In this study, to understand current health condition including the prevalence of NCDs such as DM, HT, and overweight of Tsarang residents, we established a small health clinic where we carried out medical check-ups and administered a questionnaire to examine the relationship among health, lifestyle, and socioeconomic status. Our research aims were to investigate the general health condition of the Tsarang residents to determine the risk factors for the most prevalent illness.

\section{Materials and methods}

\section{Study design, setting, and population studied}

A cross-sectional epidemiological study was carried out in July 2017 on residents 18 years old and older in Tsarang village, Dhaulagiri zone, Mustang district of Western Nepal. Mustang is located in Province number 4 which is one of the seven administrative divisions of Nepal. The total population of Tsarang was reported 452 persons $(\mathrm{M}: \mathrm{F}=217: 235)$ in 132 households. The number of males and females above the age of 18 years are 179 and 190 respectively [11]. The migration rates in Province number 4 are 27\% and 19.2\% for men and women respectively [17]. Considering the migration rates, total eligible participants in the study were 285. Assuming 95\% confidence interval, 5\% level of significance, and $50 \%$ prevalence of NCDs, the total estimated sample size was 190. Tsarang villagers were notified in advance of the small medical clinic we had set up for the survey. From those who visited the clinic, we recruited 188 participants $(\mathrm{M}: \mathrm{F}=85: 103)$ between the age of 18 and 80 years that gave a response rate of above $65 \%$. A random sampling method was used to select the study participants from the eligible population.

The questionnaire to investigate on the lifestyle, socioeconomic status, and demographic data was a modified version of the WHO Stepwise approach to surveillance (STEPs) [18]. Each participant was interviewed by a trained local nurse. We set inclusion and exclusion criteria as follows: inclusion criteria on individuals $\geq 18$ years old, who had been living at a high altitude/that research site $(\geq 3500 \mathrm{~m})$, and at present, been there for at least 3 months continuously. Exclusion criteria were pregnant women, residents with severe illness such as cancer, those refusing consent, those who are not from that mountain region, or those who have been there for less than 3 months.

\section{Biochemical and physical examinations}

Trained health care providers took anthropometric measurements for height, weight, WC, and hip circumference. Other measurements included hemoglobin $(\mathrm{Hb})$ concentration in blood, heart rate, oxygen saturation, blood pressure (BP), and glycosylated hemoglobin (HbA1c) and were taken by medically trained staffs. WC and hip circumference were measured with subjects standing and breathing normally. BMI was defined as the body mass $(\mathrm{kg}) /$ height $^{2}\left(\mathrm{~m}^{2}\right)$. BP and heart rate were measured by a digital automatic BP monitor (OMRON Model, HEM-7210, Kyoto, Japan), and an average of the two readings was recorded as participant's BP. Systolic BP (SBP) $\geq 140 \mathrm{mmHg}$ and/or diastolic BP (DBP) $\geq 90 \mathrm{mmHg}$ or self-report physician diagnosis are categorized as hypertensive [19].

To measure the level of HbA1c, blood samples were analyzed by Siemens DCA Vantage analyzer (Siemens Healthcare Diagnostics, Munich, Germany) according to the manufacturer's instructions, and the level of HbA1c was based on the National Glycohemoglobin Standardization Program (NGSP). HbA1c levels between 6 and $<6.5 \%$ are defined as intermediate hyperglycemia (IHG) or pre-DM, and at HbA1c level $\geq 6.5 \%$ as DM [20]. Hb concentration was measured by ASTRIM FIT health monitoring analyzer (Sysmex, Kobe, Japan) according to the instructions. $\mathrm{Hb}$ concentrations were classified into different groups as anemia ( $\mathrm{Hb}<13 \mathrm{~g} / \mathrm{dl}$ for males and $<12 \mathrm{~g} / \mathrm{dl}$ for females), 
normal $(\mathrm{Hb} \geq 13 \mathrm{~g} / \mathrm{dl}$ to $<18 \mathrm{~g} / \mathrm{dl}$ for males, $\mathrm{Hb} \geq 12 \mathrm{~g} / \mathrm{dl}$ to $<16 \mathrm{~g} / \mathrm{dl}$ for females), and polycythemia ( $\geq 18 \mathrm{~g} / \mathrm{dl}$ for males, $\geq 16 \mathrm{~g} / \mathrm{dl}$ for females) respectively. Oxygen saturation of $\mathrm{Hb}\left(\mathrm{SpO}_{2}\right)$ was measured by a pulse oximeter (Masimo Radical V 5.0, Masimo Corp, CA, USA). When $\mathrm{SpO}_{2} \geq 90 \%$, it was defined as normoxia. When $\mathrm{SpO}_{2}$ $<90 \%$, it was defined as hypoxemia. Overweight and obesity combined population was defined as BMI $\geq 25$ [21]. Central obesity was defined based on WC $(\geq 90 \mathrm{~cm}$ for male and $\geq 80 \mathrm{~cm}$ for female) and waist-to-hip ratio (WHR; $>0.9$ for male and $>0.85$ for female) [22].

\section{Other study variables}

To understand the socioeconomic status of participants, we investigated poverty status, education, primary occupation, and marital status. To verify poverty status, we used two different parameters, multidimensional poverty index (MPI) and income poor. MPI developed by United Nations Development Programme (UNDP) is based on identification of multiple deprivations at the household level in education, health, and standard of living and is calculated by an instruction manual [23]. Income poor is defined by the World Bank and set at $1.90 \mathrm{USD} /$ day as the international poverty line ( 1 USD $=103$ NPR). In addition, we also asked participants about family and previous histories to understand about major health concerns in participants, and about participant's behavior towards consumption of tobacco, fruits and vegetables, and alcohol as illustrated by the WHO STEPs questionnaire.

\section{Statistical analysis}

Data were analyzed by $\chi^{2}$ test and Fisher's exact test for comparison of the rates of variables and by the Welch $t$ test and Mann-Whitney $U$ test for comparison of variables between males and females. The 95\% confidential interval (CI) for a single proportion was calculated by the ClopperPearson method. In our analyses, results represented as mean \pm standard deviation (SD) were calculated using continuous variables, while results indicated as proportions (\%) with 95\% CI were using stratified variables. We conducted analyses for trend across the age groups of values to verify the statistically significant differences in each of research variables. Multiple logistic regression analysis was conducted to evaluate the relationship between the risk for the prevalence of IHG and DM combined population (IHG/ $\mathrm{DM})$ as a dependent variable and each of independent variables with expression by odds ratio (OR) with $95 \%$ CI by a backward stepwise procedure. Age, BMI, WC, SBP, DBP, $\mathrm{Hb}$ concentration, MPI poor index, and daily income were used as continuous independent variables, whereas sex, $\mathrm{SpO}_{2}$, education, primary occupation, and marital status were as categorical independent variables respectively. Akaike's information criterion (AIC) was used for comparison of logistic regression models. Tests results with $p$ values $<0.05$ were considered to be statistically significant. All statistical analyses were performed using Software R (version 3.4.1).

\section{Results \\ Demographic, lifestyle, and socioeconomic characterizations of participants}

A total of 188 participants, 85 (45.2\%) were males and 103 (54.8\%) were females between 18 and 80 years old participated in this study (Table 1). Some participants did not measure the values of HbA1c $(n=14)$ and Hb concentration $(n=10)$ due to instrument failures and severe swelling or deformity of finger joints.

Most of participants (68.1\%) had no formal education or did not finish primary school, and females (85.4\%) had almost two-fold higher proportion of no formal education than males (47.1\%). Higher proportions of males than females were employed $(43.5 \%$ vs $12.6 \%)$ and had smoking and alcohol drinking habits $(34.1 \%$ and $50.0 \%$ vs $10.7 \%$ and $17.5 \%)$. When we asked dietary habits of participants about fresh vegetable and fruits consumption, nearly $70 \%$ of participants said they consumed them around 2-3 days in a week (Table 1). On economic status, $71 \%$ of participants reported $\leq 100,000$ NPR as expected annual household income (Table 2). We used two parameters; MPI poor and income poor, which is relatively a subjective and objective indexes of poor respectively, to evaluate their economic conditions. The national levels of MPI poor and income poor in Nepal are $28.6 \%$ and $14.9 \%$, respectively [24]. As shown in Table 2, our study showed that about $27 \%$ of the participants were MPI poor, whereas almost half of the participants were as income poor, indicating that the proportion of income poor is higher than the national status of Nepal. These results indicate that people living at Tsarang have established lifestyles without being dependent on cash income and achieved a standard of living equivalent to a nationwide. By self-reports about family and previous histories, many participants complained of joint pain, indicating that arthritis or osteoarthritis might be a major health concerns in participants (Table 2).

\section{Anthropometric and biochemical characteristics by sex and age}

BMI, WC, and WHR were calculated to find the prevalence of overweight, obesity, and central obesity respectively. The combination of being overweight and obese was observed in $29.3 \%$ of participants with no significant difference between sexes (Table 3 ). Central obesity calculated by WHR had higher prevalence in females than males with rates of $59.4 \%$ and $40.2 \%$ respectively, whereas by WC, it had $23.5 \%$ in total, with females having higher prevalence of $31.1 \%$ than males who had it $14.3 \%$. $27.1 \%$ for 
Table 1 Demographic and lifestyle characterizations of participants by gender

\begin{tabular}{|c|c|c|c|c|}
\hline Variables & All & Male & Female & $P$ value \\
\hline $\operatorname{Sex}(n)$ & 188 & $85(45.21)$ & $103(54.79)$ & \\
\hline Age (mean $\pm S D)$ & $46.31 \pm 14.66$ & $45.74 \pm 13.40$ & $46.79 \pm 15.67$ & 0.6694 \\
\hline Age (median; IQR) & $45(22)$ & $43(20)$ & $47(25)$ & \\
\hline \multicolumn{5}{|l|}{ Marital status (\%) ${ }^{a}$} \\
\hline Currently married & $62.77(55.39-69.61)$ & $75.29(64.54-83.73)$ & $52.43(42.40-62.27)$ & \multirow[t]{2}{*}{0.0017} \\
\hline Not currently married & $36.17(29.39-43.52)$ & $24.71(16.27-35.46)$ & $45.63(35.88-55.71)$ & \\
\hline \multicolumn{5}{|l|}{ Education (\%) } \\
\hline No schooling & $68.09(60.84-74.58)$ & $47.06(36.25-58.13)$ & $85.44(76.80-91.35)$ & \multirow[t]{4}{*}{$<0.0001$} \\
\hline Less than primary school completed & $6.91(3.89-11.79)$ & $11.76(6.09-21.01)$ & $2.91(0.76-8.90)$ & \\
\hline Less than secondary school completed & $12.23(8.07-17.99)$ & $20.00(12.40-30.36)$ & $5.83(2.39-12.75)$ & \\
\hline More higher education & $12.77(8.51-18.59)$ & $21.18(13.36-31.65)$ & $5.83(2.39-12.75)$ & \\
\hline \multicolumn{5}{|l|}{ Primary occupation (\%) } \\
\hline Employed & $26.60(20.55-33.61)$ & $43.53(32.95-54.70)$ & $12.62(7.16-20.97)$ & \multirow[t]{2}{*}{$<0.0001$} \\
\hline Unemployed & $73.40(66.39-79.45)$ & $56.47(45.30-67.05)$ & $87.38(79.03-92.84)$ & \\
\hline \multicolumn{5}{|l|}{ Smoking habits (\%) } \\
\hline Current/Ex-smoker & $21.28(15.80-27.96)$ & $34.12(24.40-45.29)$ & $10.68(5.71-18.69)$ & \multirow[t]{2}{*}{0.0002} \\
\hline Non smoker & $78.72(72.04-84.20)$ & $65.88(54.71-75.60)$ & $89.32(81.31-94.29)$ & \\
\hline \multicolumn{5}{|l|}{ Alcohol drinking habits (\%) ${ }^{b}$} \\
\hline Current/Ex-drinker & $32.09(25.57-39.35)$ & $50.00(39.54-60.46)$ & $17.48(10.96-26.48)$ & \multirow[t]{2}{*}{$<0.0001$} \\
\hline Non drinker & $67.91(60.65-74.43)$ & $50.00(39.54-60.46)$ & $82.52(73.52-89.04)$ & \\
\hline \multicolumn{5}{|l|}{ Vegetable consumption (in a week; \%) } \\
\hline Less than once & $14.44(9.89-20.49)$ & $19.05(11.60-29.38)$ & $10.68(5.71-18.69)$ & \multirow[t]{3}{*}{0.2123} \\
\hline $2-3$ days & $65.24(57.90-71.95)$ & $59.52(48.24-69.93)$ & $69.90(59.95-78.34)$ & \\
\hline More than 4 days & $20.32(14.94-26.95)$ & $21.43(13.52-31.40)$ & $19.42(12.54-28.63)$ & \\
\hline \multicolumn{5}{|l|}{ Vegetable and fruit serving (in a day; \%) } \\
\hline Less than one & $18.18(13.08-24.62)$ & $20.24(12.56-30.70)$ & $16.50(10.18-25.40)$ & \multirow[t]{3}{*}{0.2385} \\
\hline $2-3$ servings & $68.98(61.75-75.42)$ & $63.10(51.81-73.17)$ & 73.79 (64.03-81.73) & \\
\hline More than 4 servings & $12.83(8.56-18.69)$ & $16.67(9.73-26.73)$ & $9.71(5.01-17.54)$ & \\
\hline
\end{tabular}

Values are in percentage $(95 \% \mathrm{Cl})$. Data were analyzed by $X^{2}$ test or Fisher's exact test for comparison of the rates of variables and by the Mann-Whitney U-test for comparison of variables between males and females

$S D$ standard deviation, IQR interquartile range, $\mathrm{Cl}$ confidential interval

${ }^{\text {a } T w o ~ p a r t i c i p a n t s ~ r e f u s e d ~ t o ~ a n s w e r ~}$

${ }^{b}$ One participant refused to answer

males versus $15.5 \%$ for females were hypertensive. A total of $20.7 \%$ of participants were hypertensive and most had normal $\mathrm{Hb}$ concentration. To examine the prevalence of type $2 \mathrm{DM}$ in participants, we measured HbA1c because this value is considered to be a good risk marker for the development of type 2 DM [25]. In this study, we found that $31.6 \%$ and $4.6 \%$ of participants were classified as IHG and DM respectively (Table 3). The prevalence of DM as well as IHG increased steadily as the age advanced. Among the age group $\leq 40$ years, almost all participants had normal range of $\mathrm{HbA1c}$, whereas the prevalence of IHG/DM rose dramatically for those over 40 years of age (Table 4 ).

\section{Factors that affect participants' health}

To estimate the association between the risk for IHG/DM in participants and research variables (sex, age, BMI, WC, $\mathrm{SpO}_{2}$, SBP, DBP, Hb concentration, MPI index, daily income, education, marital status, primary occupation), we first conducted univariate logistic regression analyses of each of variables (Table 5). In the univariate regression analyses, the prevalence of IHG/DM was positively associated with age $(p<0.0001$, for every 1 year increase) and $\mathrm{Hb}$ concentration ( $p=0.0339$, for every one unit increase). In addition, participants with hypoxemia $(p<0.0001)$ were at the increased risk for the prevalence of IHG/DM than persons with normoxia. We next performed an analysis to 
Table 2 Socioeconomic characterization and disease history of participants

\begin{tabular}{|c|c|}
\hline Factors & $n(\%)$ \\
\hline \multicolumn{2}{|l|}{ Expected annual income (NPR) ${ }^{\mathrm{a}}$} \\
\hline$\leq 10,000$ & $22(12.29)$ \\
\hline 10,001 to $\leq 50,000$ & $43(24.02)$ \\
\hline 50,001 to $\leq 100,000$ & $62(34.64)$ \\
\hline$>100,000$ & $52(29.05)$ \\
\hline \multicolumn{2}{|l|}{ Poverty } \\
\hline MPI poor ${ }^{b}$ & $51(27.27)$ \\
\hline Income poor ${ }^{a}$ & $90(50.28)$ \\
\hline \multicolumn{2}{|l|}{ Family history ${ }^{c}$} \\
\hline Arthritis & $74(41.11)$ \\
\hline Hypertension & $18(10.00)$ \\
\hline Rheumatism & $11(6.11)$ \\
\hline Others $^{\mathrm{d}}$ & $6(3.33)$ \\
\hline \multicolumn{2}{|l|}{ Previous history $^{c}$} \\
\hline Hypertension (or raised blood pressure) & $32(17.02)$ \\
\hline Diabetes (or raised blood sugar) & $6(3.19)$ \\
\hline Allergy & $60(32.26)$ \\
\hline Osteoarthritis $^{e}$ & $116(62.70)$ \\
\hline
\end{tabular}

${ }^{\mathrm{a}} 9$ participants are excluded because they do not know their own annual income

${ }^{\mathrm{b}} \mathrm{MPI}$ poor is defined as deprivation score $\geq 33.3 \%$ [23]. MPI, multidimensional poverty index

'Self-reported by participants

dIncluding allergy, diabetes, and obesity

eIncluding joint pain, swollen joints, and stiff joints

identify the association between the prevalence of IHG/DM and multivariate confounding factors by a stepwise multiple logistic regression analysis. On this analysis, age, BMI, $\mathrm{SpO}_{2}, \mathrm{SBP}, \mathrm{Hb}$ concentration, and marital status remained as confounders, and therefore we conducted further calculation of ORs for the prevalence of IHG/DM using those remaining confounders as independent variables. As shown in Table 5, age $(\mathrm{OR}=1.113,95 \% \mathrm{CI}=$ $1.063-1.165, p<0.0001$, for every 1 year increase) and BMI $(\mathrm{OR}=1.260,95 \% \mathrm{CI}=1.081-1.468, p=0.0031$, for every one point increase) were found to be positively associated with the prevalence of IHG/DM. Residents with hypoxemia were at the increased prevalence for the IGH/DM compared to participants with normoxia (OR $=3.577$, 95\% $\mathrm{CI}=1.198-10.678, p=0.0224$, vs normoxia). In addition, unmarried participants had a significantly increased prevalence for IHG/DM than married participants $(\mathrm{OR}=2.717$, $95 \% \mathrm{CI}=1.001-7.374, p=0.0498$, vs currently married participants).

\section{Discussion}

The present study is an epidemiological investigation of rural highlanders of Mustang district, Nepal, that included information on demography, socioeconomic and current health condition. As shown in previous reports, the prevalence of NCDs in Nepal is increasing in recent years, and therefore NCDs are recognized as an emerging health concern $[6,26]$. To our knowledge, epidemiological information on NCD prevalence in the Mustang district is limited, and it is difficult to accurately assess the health status of isolated villages.

Our study showed the prevalence of overweight and obese participants to be $29.3 \%$ (95\% CI $=23.0-36.4 \%)$. A study conducted at other villages in Mustang district, Nepal, reported the prevalence of overweight and obese population at the rural setting to be $26.7 \%$ whereas at the urban settings to be $47.7 \%$ and $56.6 \%$ respectively [27]. A possible reason behind these differences may be associated with economic status. In addition, a nationwide survey in Nepal done in 2013 showed the prevalence of overweight and obese population that inhabitants of the mountain regions to be $9.0 \%$ (95\% CI $=4.6-17.0 \%)$ [6]. These differences between Tibetans in Mustang district and nationwide survey could be attributed to be Tibetans' increased preference for high consumption of carbohydrates and physical inactivity coined with low education level of the population studied [28]. The prevalence of pre-DM or IHG in our study participants was $31.6 \%(95 \% \mathrm{CI}=24.9-39.2 \%)$ (Table 3). Our result is similar as in other findings examining the prevalence of IHG in different villages that have the same ethnic background as in our study. For instance, research at other villages in Mustang district has observed the prevalence of IHG ranging from $22.1-39.3 \%$ [27]. In addition, examining of the prevalence of IHG at the same altitude in China and India ranged from 22.3-41.6\% $[29,30]$. On the other hand, a meta-analysis of data that examined the prevalence of DM and IHG in Nepal found pre-DM population to be $10.3 \%(95 \% \mathrm{CI}=6.1-14.4 \%)$ [10]. The study population for this meta-analysis included various ethnic groups not restricted to a specific profession. Therefore, these observations indicate that ethnicity, lifestyle habits, and socio-economic characteristics may attribute to these observed differences.

On a stepwise multiple logistic regression analysis, we found that lifestyle and health-related factors were significantly associated with the prevalence of IHG/DM in our participants (Table 5). Note that, participants with hypoxemia had increased prevalence of IHG/DM compared with participants with normoxia. A previous study has shown that hypoxemia plays a role in the high prevalence of glucose intolerance in Tibetan people of India and China [30]. Although, regarding the association between hypoxemia and glucose intolerance or elevation of $\mathrm{HbA1c}$ levels, several reports related to patients with sleep disorder could find that there is significant correlation between $\mathrm{HbA} 1 \mathrm{c}$ or blood glucose level and $\mathrm{SpO}_{2}$, associated mechanisms of hypoxemia with glucose intolerance are not clearly known [31, 32]. We speculate a possible mechanism that 
Table 3 Anthropometric and biochemical characteristics of studied variables by sex

\begin{tabular}{|c|c|c|c|c|}
\hline Variables & Total & Male & Female & $P$ value \\
\hline Height (cm) & $157.11 \pm 9.30$ & $164.18 \pm 6.81$ & $151.27 \pm 6.66$ & $<0.0001$ \\
\hline Weight (kg) & $57.59 \pm 10.44$ & $62.59 \pm 9.39$ & $53.46 \pm 9.45$ & $<0.0001$ \\
\hline $\mathrm{BMI}$ & $23.28 \pm 3.43$ & $23.21 \pm 3.17$ & $23.34 \pm 3.64$ & 0.8780 \\
\hline Overweight (BMI $\geq 25$ ) (\%) & $29.26(22.98-36.40)$ & $30.59(21.30-41.66)$ & $28.16(19.95-38.01)$ & 0.8384 \\
\hline WC (cm) & $77.27 \pm 8.68$ & $79.43 \pm 8.42$ & $75.50 \pm 8.52$ & 0.0017 \\
\hline$\geq 90 \mathrm{~cm}$ (male)/ $\geq 80 \mathrm{~cm}$ (female) (\%) & $23.53(17.78-30.39)$ & $14.29(7.92-24.02)$ & $31.07(22.52-41.05)$ & 0.0118 \\
\hline $\operatorname{Hip}(\mathrm{cm})^{\mathrm{a}}$ & $88.86 \pm 7.92$ & $90.00 \pm 7.23$ & $87.94 \pm 8.36$ & 0.0499 \\
\hline$W H R^{a}$ & $0.87 \pm 0.05$ & $0.88 \pm 0.06$ & $0.86 \pm 0.05$ & 0.0062 \\
\hline$>0.9$ (male) $/>0.85$ (female) $(\%)$ & $50.82(43.37-58.24)$ & $40.24(29.74-51.67)$ & $59.41(49.16-68.93)$ & 0.0151 \\
\hline $\mathrm{SpO}_{2}(\%)$ & $90.60 \pm 3.21$ & $90.47 \pm 3.48$ & $90.71 \pm 2.97$ & 0.9913 \\
\hline Hypoxemia $\left(\mathrm{SpO}_{2}<90 \%\right)(\%)$ & $27.13(21.04-34.17)$ & $28.24(19.26-39.20)$ & $26.21(18.27-35.97)$ & 0.8843 \\
\hline Heart rate (bpm) & $81.57 \pm 12.13$ & $81.35 \pm 13.74$ & $81.76 \pm 10.68$ & 0.8249 \\
\hline $\mathrm{SBP}(\mathrm{mmHg})$ & $122.67 \pm 18.22$ & $128.36 \pm 16.77$ & $117.97 \pm 18.11$ & $<0.0001$ \\
\hline$\geq 140 \mathrm{mmHg}(\%)$ & $17.02(12.09-23.33)$ & $23.53(15.29-34.20)$ & $11.65(6.43-19.84)$ & 0.0498 \\
\hline $\mathrm{DBP}(\mathrm{mmHg})$ & $77.07 \pm 11.61$ & $79.67 \pm 10.72$ & $74.92 \pm 11.92$ & 0.0030 \\
\hline$\geq 90 \mathrm{mmHg}(\%)$ & $13.30(8.95-19.19)$ & $16.47(9.62-26.43)$ & $10.68(5.72-18.69)$ & 0.3431 \\
\hline$H T^{\mathrm{b}}$ & $20.74(15.33-27.39)$ & $27.06(18.26-37.96)$ & $15.53(9.41-24.30)$ & 0.0786 \\
\hline $\mathrm{Hb}(\mathrm{g} / \mathrm{dL})^{\mathrm{c}}$ & $13.82 \pm 1.74$ & $14.48 \pm 1.42$ & $13.33 \pm 1.80$ & $<0.0001$ \\
\hline$<13$ (male) $/<12$ (female) (\%) & $17.42(12.31-23.97)$ & $14.47(7.79-24.85)$ & $19.61(12.66-28.89)$ & 0.0028 \\
\hline 13 to $<18$ (male)/12 to < 16 (female) (\%) & $76.40(69.35-82.29)$ & $85.53(75.15-92.91)$ & $69.61(59.59-78.12)$ & \\
\hline$\geq 18$ (male)/ $\geq 16$ (female) (\%) & $6.18(3.28-11.07)$ & 0 & $10.78(5.77-18.87)$ & \\
\hline $\mathrm{HbA1c}(\mathrm{NGSP} ; \%)^{\mathrm{d}}$ & $5.96 \pm 0.99$ & $5.90 \pm 1.00$ & $6.01 \pm 0.98$ & 0.1051 \\
\hline 6.0 to $<6.5 \%(\%)$ & $31.61(24.90-39.15)$ & $27.27(18.04-38.81)$ & $35.05(25.83-45.48)$ & 0.5544 \\
\hline$\geq 6.5 \%(\%)$ & $4.60(2.15-9.17)$ & $5.19(1.68-13.47)$ & $4.12(1.33-10.82)$ & \\
\hline
\end{tabular}

Values are mean $\pm S D$ and percentage $(95 \% \mathrm{Cl})$. Data were analyzed by $x^{2}$ test or Fisher's exact test for comparison of the rates of variables and by the Welch $\mathrm{t}-$ test or Mann-Whitney U-test for comparison of variables between males and females

$B M I$ body mass index, WC waist circumference, WHR waist-to-hip ratio, SBP systolic blood pressure, DBP diastolic blood pressure, $H T$ hypertension, $H b$ hemoglobin, $S D$ standard deviation, $\mathrm{Cl}$ confidential interval

$a_{5}$ participants refused measurement

$b^{b} \geq 140 \mathrm{mmHg} S B P$ and/or $\geq 90 \mathrm{mmHg}$ DBP in participants

${ }^{c} 10$ participants could not be measured due to severe deformation of finger joint or machine troubles

${ }^{d} 14$ participants could not be measured due to machine troubles

hypoxic environment generates both hypoxemia and oxidative stress, causing induction of expression of many genes including that related to inflammatory pathways, resulting in hyperglycemia [33-35]. In addition, both elevation of HbA1c value and the prevalence of hypoxemia are accelerated by aging process [30, 36, 37]. When we examined the correlation of age with $\mathrm{SpO}_{2}$ or $\mathrm{HbA1c}$ in participants by Spearman rank correlation tests, $\mathrm{SpO}_{2}(\rho=-0.535, p<0.0001)$ was negatively associated with age, whereas HbA1c $(\rho=0.554, p<0.0001)$

Table 4 Prevalence of IHG/DM in sex by age groups

\begin{tabular}{|c|c|c|c|c|c|c|}
\hline & \multicolumn{3}{|l|}{ Male $(n=77)$} & \multicolumn{3}{|l|}{ Female $(n=97)$} \\
\hline & $\mathrm{HbA} 1 \mathrm{c}<6.0 \%$ & $\mathrm{HbA} 1 \mathrm{c} \geq 6.0 \%$ & $P$ for trend & $\mathrm{HbA} 1 \mathrm{c}<6.0 \%$ & $\mathrm{HbA} 1 \mathrm{c} \geq 6.0 \%$ & $P$ for trend \\
\hline Age $\leq 30$ & 6 & 1 & 0.0002 & 16 & 1 & $<0.0001$ \\
\hline 31 to $\geq 40$ & 22 & 1 & & 16 & 3 & \\
\hline 41 to $\geq 50$ & 13 & 8 & & 12 & 9 & \\
\hline 51 to $\geq 60$ & 7 & 9 & & 11 & 9 & \\
\hline$>60$ & 4 & 6 & & 4 & 16 & \\
\hline
\end{tabular}

Data were analyzed by Cochran-Armitage trend test for comparison of prevalence of participants. IHG/DM, intermediate hyperglycemia and diabetes mellitus combined population 
Table 5 Stepwise logistic regression analyses to evaluate relationships between research variables and the prevalence of IHG/DM

\begin{tabular}{|c|c|c|c|c|c|c|}
\hline \multirow[t]{2}{*}{ Variables } & \multicolumn{3}{|l|}{ Crude } & \multicolumn{3}{|c|}{ Adjusted } \\
\hline & OR & $95 \% \mathrm{Cl}$ & $P$ value & OR & $95 \% \mathrm{Cl}$ & $P$ value \\
\hline Age & 1.1111 & $1.0736-1.1562$ & $<0.0001$ & 1.1128 & $1.0631-1.1647$ & $<0.0001$ \\
\hline BMl & 1.0537 & $0.9499-1.1703$ & 0.3220 & 1.2596 & $1.0811-1.4675$ & 0.0031 \\
\hline \multicolumn{7}{|l|}{$\mathrm{SpO}_{2}$} \\
\hline$\geq 90 \%$ & Ref & & & Ref & & \\
\hline$<90 \%$ (hypoxemia) & 7.9222 & $3.4488-19.3937$ & $<0.0001$ & 3.5769 & $1.1983-10.6775$ & 0.0224 \\
\hline $\mathrm{Hb}$ concentration & 1.2370 & $1.0200-1.5150$ & 0.0339 & 1.3093 & $0.9845-1.7412$ & 0.0634 \\
\hline SBP & 0.9999 & $0.9813-1.0182$ & 0.9920 & 0.9778 & $0.9532-1.0030$ & 0.0832 \\
\hline \multicolumn{7}{|l|}{ Marital status } \\
\hline Currently & Ref & & & Ref & & \\
\hline Not currently & 1.9397 & $0.9513-3.9548$ & 0.0673 & 2.7168 & $1.0009-7.3741$ & 0.0498 \\
\hline \multicolumn{7}{|l|}{ Sex } \\
\hline Male & Ref & & & & & \\
\hline Female & 1.6941 & 0.8479-3.4699 & 0.1408 & & & \\
\hline WC & 1.0343 & $0.9952-1.0761$ & 0.0892 & & & \\
\hline DBP & 0.9956 & $0.9667-1.0247$ & 0.7670 & & & \\
\hline MPI poor index & 1.1112 & $0.0753-15.2549$ & 0.9374 & & & \\
\hline Daily income & 0.9608 & $0.8656-1.0524$ & 0.4145 & & & \\
\hline \multicolumn{7}{|l|}{ Education } \\
\hline Less than primary school completed & Ref & & & & & \\
\hline Less than secondary school completed & 0.4286 & $0.1169-1.2598$ & 0.1522 & & & \\
\hline More higher education & 0.4571 & $0.1241-1.3564$ & 0.1885 & & & \\
\hline \multicolumn{7}{|l|}{ Primary occupation } \\
\hline Employed & Ref & & & & & \\
\hline Unemployed & 1.7222 & $0.7855-4.0305$ & 0.1888 & & & \\
\hline AIC & & - & & & 140.13 & \\
\hline
\end{tabular}

Univariate logistic regression analyses were conducted to the association between the prevalence of IHG/DM and each of variables by expression of OR with $95 \%$ $\mathrm{CI}$ (left). After conduction of a stepwise multiple logistic regression analysis using all research variables, ORs were calculated using remained confounders by a multiple logistic regression analysis (right)

IHG/DM intermediate hyperglycemia and diabetes mellitus combined population, $O R$ odds ratio, $\mathrm{Cl}$ confidential interval, $B M I$ body mass index, $\mathrm{Hb}$ hemoglobin, SBP systolic blood pressure, WC waist circumference, DBP diastolic blood pressure, MPI multidimensional poverty index, AIC Akaike's Information Criterion, DM diabetes mellitus

was positively, indicating that both prevalence of hypoxemia and IHG are dependent on aging. Therefore, we speculate that aging process causes hypoxemia and glucose intolerance, despite normal $\mathrm{Hb}$ concentration among elderly participants (Table 6 ). In the present study, the prevalence of IHG was remarkably high (31.6\%), particularly among the participants above the age of 40 years. This suggests that there will be an increased burden of DM at the study site as the population ages. The challenge for future research efforts should focus on prevention and control measures for NCDs in rural highlands in areas with limited access. Early detection, screening, and treatment of NCDs, as well as palliative care, are key components of the response to NCDs which present a serious challenge to resources in developing countries such as Nepal. Hence, sustainable and effective measures for detection, screening, and treatment of NCDs targeting the rural highlanders in
Nepal need to be urgently developed. The results from our study may contribute to the limited body of research which we hope will lead to effective measures for detection, screening, and treatments of NCDs.

In this study, we found that hypoxemia, age, BMI, and marital status are the factors for the high prevalence of IHG/DM (Table 5). Previous studies have shown that many Tibetan residents living at high altitude have low oxygen saturation levels $[38,39]$. Therefore, we speculate that hypoxemia is one of the common factors for the high prevalence of IHG/DM in Tibetan highlanders because our finding is in accordance with previous reports from different countries of the same ethnic population from different countries [30]. Further research in other high-altitude communities as well as lowland residents with the same ethnic background may confirm the risk factors that our study has revealed, and it may lead to 
Table $\mathbf{6}$ Tendency and prevalence of variables in sex by age groups

\begin{tabular}{llllll}
\hline Sex & Variables & Age $\leq 40$ & 41 to $\leq 60$ & $>60$ & $P$ for trend \\
\hline Male & $\mathrm{Hb}(\mathrm{g} / \mathrm{dL})^{\mathrm{a}}$ & $14.72 \pm 1.44$ & $14.51 \pm 1.38$ & $13.65 \pm 1.31$ & 0.0328 \\
& $\mathrm{SpO}_{2}(\%)^{\mathrm{a}}$ & $92.27 \pm 1.59$ & $89.53 \pm 3.65$ & $88.79 \pm 4.51$ & $<0.0001$ \\
& $\mathrm{HG} / \mathrm{DM}(\%)^{\mathrm{b}}$ & $6.67(1.16-23.51)$ & $45.95(29.85-62.87)$ & $60.00(27.37-86.31)$ & 0.0001 \\
Female & $\mathrm{Hb}(\mathrm{g} / \mathrm{dL})^{\mathrm{a}}$ & $12.61 \pm 1.69$ & $13.59 \pm 1.62$ & $14.05 \pm 1.91$ & 0.0004 \\
& $\mathrm{SpO}_{2}(\%)^{\mathrm{a}}$ & $92.39 \pm 1.67$ & $90.62 \pm 2.87$ & $88.09 \pm 2.97$ & $<0.0001$ \\
& $\mathrm{HHG} / \mathrm{DM}(\%)^{b}$ & $11.11(3.62-27.00)$ & $43.90(28.82-60.11)$ & $80.00(55.73-93.39)$ & $<0.0001$ \\
\hline
\end{tabular}

$\mathrm{Hb}$ hemoglobin, IHG/DM intermediate hyperglycemia and diabetes mellitus combined population

a Values are mean \pm SD. Data were analyzed by Jonckheere-Terpstra trend test for comparison of means of variables among age. SD, standard deviation

${ }^{b}$ Values are represented as proportion of prevalence of IHG/DM $(95 \% \mathrm{Cl})$. Data were analyzed by Cochran-Armitage trend test for comparison of proportion of IHG/DM among age groups. Cl, confidential interval

establishing appropriate prevention and control strategies of cardio-metabolic diseases in the highland areas of Nepal. In addition, it has been recently shown that genetic polymorphisms in the gene encoding EGLN1 and in mitochondrial-DNA (mtDNA) are associated with $\mathrm{SpO}_{2}$ responses $[40,41]$. However, these studies were conducted in lowland Japanese cohort and in the acute hypobaric hypoxia. So, it might be difficult to discuss this association because our study population is different ethnic groups and highland residents. But, such genetic studies will provide the new insight into the effects in physiological responses of our study population.

It should be noted that this study has several limitations. The first is the involvement of only one research site which was a result of difficult access. However, this study has encouraged us to confirm our findings in other areas and follow up studies. Second, we measured $\mathrm{HbA1c}$ as a diagnostic test for IHG and DM. This survey did not measure fasting blood samples which could have given the definitive diagnosis. However, HbA1c requires no patient preparation, e.g., fasting before blood collection, which could be difficult because of participants' education levels and cultural views. The present study has shed light on our limitation and encouraged us for our next research plan to evaluate the associations between genetic polymorphisms of our population and their physiology of hypoxemia or the disease processes.

\section{Conclusions}

Our results suggest that there is an increased prevalence of IHG/DM for hypoxic people of 40 years of age and above in Tsarang village of rural Nepal suggesting an urgent need for prioritizing public health concern for NCDs. The association of hypoxemia and prevalence of IHG/DM as shown by this study could be due to the additive effects of hypoxia, lifestyle or dietary habits, and genetic predisposition of the Tibetan highlanders. More population-specific studies are the required to aim for estimation of prevalence, prevent, and control NCDs in the mountainous regions.

\section{Abbreviations}

AIC: Akaike's information criteria; BMI: Body mass index; BP: Blood pressure; $\mathrm{Cl}$ : Confidence interval; DBP: Diastolic blood pressure; DM: Diabetes mellitus; Hb: Hemoglobin; HbA1c: Glycosylated hemoglobin; HT: Hypertension; IHG: Intermediate hyperglycemia; MPI: Multidimensional poverty index; NCDs: Noncommunicable diseases; OPHI: Oxford poverty and human development initiative; OR: Odds ratio; SBP: Systolic blood pressure; $\mathrm{SpO}_{2}$ : Oxygen saturation of hemoglobin; STEPs: Stepwise approach to surveillance; UNDP: United Nations Development Programme; WC: Waist circumference; WHO: World Health Organization; WHR: Waist-to-hip ratio

\section{Acknowledgements}

We appreciate all the highlanders who participated in the community-based examination and research. We would like to express our cordial gratitude to the staffs of Tsarang health-post and Mustang district hospital that kindly helped us.

\section{Funding}

This work was supported by JSPS KAKENHI grant numbers $16 \mathrm{H} 07075$ and 17H04659, Grant-in-aid of Asia-Oceania collaborative research from Kanae foundation for the promotion of medical science, the research grant from the Japan Prize Foundation, the Joint Usage/Research Center on Tropical Disease, Institute of Tropical Medicine, Nagasaki University (2017-Ippan-29), and Program for Nurturing Global Leaders in Tropical and Emerging Communicable Diseases, Graduate School of Biomedical Sciences, Nagasaki University.

\section{Availability of data and materials}

All data used in this study are not publicly available due to use for our further studies, but scientifically appropriate request will be available after considering by ethical committees.

\section{Authors' contributions}

SK, MN, and TY contributed to the design of this study as well as writing this manuscript. SK, MN, HA, TN, TI, HI, TW, and TY performed data collection from participants. MN and ST performed conduction of statistical analyses. BDP and KP contributed to the managements of this study in Nepal, negotiation with local persons and authorities, evaluation of collected and analyzed data, and the revision of this manuscript. All authors read and approved the final manuscript.

\section{Ethics approval and consent to participate}

This study was approved by the ethical committees of the Nepal health research council (approval no. 142/2016) and Institution of Tropical Medicine, Nagasaki University (approval no. 150226137-3). Each respondent who participated in the study was given detailed information about the research objectives, data collection procedures, benefit, risk, and confidentiality before written informed consent was obtained from all the participants along with thumb impression, if participants were unable to write.

\section{Consent for publication}

Authors obtained written informed consent from all participants after explanation about data usage for publication. 


\section{Competing interests}

The authors declare that they have no competing interests.

\section{Publisher's Note}

Springer Nature remains neutral with regard to jurisdictional claims in published maps and institutional affiliations.

\section{Author details}

'Department of International Health, Institute of Tropical Medicine, Nagasak University, 1-12-4 Sakamoto, Nagasaki 852-8523, Japan. 'Leading Program, Graduate School of Biomedical Sciences, Nagasaki University, 1-12-4 Sakamoto, Nagasaki 852-8523, Japan. ${ }^{3}$ Graduate School of Biomedical Sciences, Nagasaki University, 1-12-4 Sakamoto, Nagasaki 852-8523, Japan. ${ }^{4}$ Department of Bacteriology, Institute of Tropical Medicine, Nagasaki University, 1-12-4 Sakamoto, Nagasaki 852-8523, Japan. ${ }^{5}$ Department of Nutrition Science, Faculty of Nursing and Nutrition, University of Nagasaki, 1-1-1 Manabino, Nagayo, Nishisonogi, Nagasaki 851-2195, Japan. ${ }^{6}$ Department of Society and Regional Culture, Okinawa International University, 2-6-1 Ginowan, Ginowan City, Okinawa 901-2701, Japan. ${ }^{7}$ Department of Public Health, Graduate School of Biomedical Sciences, Nagasaki University, 1-12-4 Sakamoto, Nagasaki, Japan. ${ }^{8}$ Department of General System Studies, Graduate School of Arts and Sciences, University of Tokyo, 3-8-1 Komaba, Meguro, Tokyo 153-8902, Japan. ${ }^{9}$ Everest International Clinic and Research Center, GPO 9045, Kathmandu, Nepal. ${ }^{10}$ National Center for AIDS \& STD Control, Ministry of Health and Population, GPO 9045, Teku, Kathmandu, Nepal. ${ }^{11}$ Department of Environmental Sciences, Zoology, University of Basel, Vesalgasse 1, CH-4051 Basel, Switzerland. ${ }^{12} \mathrm{Nepal}$ Academy of Science and Technology, GPO 3323, Khumaltar, Lalitpur, Nepal.

${ }^{13}$ School of Tropical Medicine and Global Health, Nagasaki University, 1-12-4 Sakamoto, Nagasaki 852-8523, Japan.

\section{Received: 18 June 2018 Accepted: 17 August 2018}

\section{Published online: 29 August 2018}

\section{References}

1. Dye C. After 2015: infectious diseases in a new era of health and development. Philos Trans R Soc Lond Ser B Biol Sci. 2014;369:20130426.

2. NCD Risk Factor Collaboration. Worldwide trends in diabetes since 1980: a pooled analysis of 751 population-based studies with 4.4 million participants. Lancet. 2016;387:1513-30.

3. Bygbjerg IC. Double burden of noncommunicable and infectious diseases in developing countries. Science. 2012;337:1499-501.

4. World Health Organization. Global status report on noncommunicable diseases 2010: WHO press; 2011a. http://www.who.int/nmh/publications/ ncd_report_full_en.pdf. Accessed 16 Nov 2017

5. World Health Organization. Noncommunicable diseases, fact sheet: WHO Media centre; 2017a. http://www.who.int/mediacentre/factsheets/fs355/en/. Accessed 10 Nov 2017

6. Aryal KK, Mehata S, Neupane S, Vaidya A, Dhimal M, Dhakal P, et al. The burden and determinants of non-communicable diseases risk factors in Nepal: findings from a nationwide STEPs survey. PLoS One. 2015;10: e0134834.

7. World Health Organization. Noncommunicable diseases country profiles 2014: WHO; 2014. http://who.int/nmh/countries/en/. Accessed 16 Nov 2017

8. Government of Nepal. Multisectoral action plan for the prevention and control of non communicable diseases (2014-2020): WHO; 2014. http:// www.searo.who.int/nepal/mediacentre/ncd_multisectoral_action_plan.pdf. Accessed 15 Nov 2017

9. Neupane D, McLachlan CS, Sharma R, Gyawali B, Khanal V, Mishra SR, et al. Prevalence of hypertension in member countries of South Asian Association for Regional Cooperation (SAARC): systematic review and meta-analysis. Medicine. 2014;93:e74

10. Gyawali B, Sharma R, Neupane D, Mishra SR, van Teijlingen E, Kallestrup P. Prevalence of type 2 diabetes in Nepal: a systematic review and metaanalysis from 2000 to 2014. Glob Health Action. 2015;8:29088.

11. Central Bureau of Statistics. National population and housing census 2011 (National report). Government of Nepal, National planning commission secretariat. 2012. https://unstats.un.org/unsD/demographic/sources/census/ wphc/Nepal/Nepal-Census-2011-Vol1.pdf. Accessed 1 Nov 2017.

12. Beall CM. Two routes to functional adaptation: Tibetan and Andean highaltitude natives. Proc Natl Acad Sci U S A. 2007;104(Suppl 1):8655-60.
13. Quintero P, Milagro FI, Campión J, Martínez JA. Impact of oxygen availability on body weight management. Med Hypotheses. 2010;74:901-7.

14. Mingji C, Onakpoya IJ, Perera R, Ward AW, Heneghan CJ. Relationship between altitude and the prevalence of hypertension in Tibet: a systematic review. Heart. 2015;101:1054-60.

15. Bernabé-Ortiz A, Carrillo-Larco RM, Gilman RH, Checkley W, Smeeth L, Miranda JJ, et al. Impact of urbanization and altitude on the incidence of, and risk factors for, hypertension. Heart. 2017;103:827-33.

16. Sherpa LY, Deji SH, Chongsuvivatwong V, Thelle DS, Bjertness E. Obesity in Tibetans aged 30-70 living at different altitudes under the north and south faces of Mt. Everest. Int J Environ Res Public Health. 2010;7:1670-80.

17. Ministry of Health Nepal, New ERA, ICF. Nepal Demographic and Health Survey 2016. Ministry of Health, Nepal. p. 2017. https://www.dhsprogram. com/pubs/pdf/fr336/fr336.pdf. Accessed 21 Mar 2018

18. World Health Organization. WHO STEPS surveillance manual: WHO; 2017b. http://www.who.int/chp/steps/STEPS_Manual.pdf?ua=1. Accessed 11 Nov 2017

19. James PA, Oparil S, Carter BL, Cushman WC, Dennison-Himmelfarb C, Handler J, et al. 2014 evidence-based guideline for the management of high blood pressure in adults: report from the panel members appointed to the Eighth Joint National Committee (JNC 8). JAMA. 2014;311:507-20.

20. World Health Organization. Use of glycated haemoglobin $(\mathrm{HbA} 1 \mathrm{c})$ in the diagnosis of diabetes mellitus. Abbreviated report of a WHO consultation: WHO press; 2011 b. http://www.who.int/diabetes/publications/report-hbalc_ 2011.pdf. Accessed 16 Nov 2017

21. World Health Organization. Obesity and overweight, fact sheet: WHO Media centre; 2017c. http://www.who.int/mediacentre/factsheets/fs311/en/. Accessed 10 Nov 2017

22. World Health Organization. Waist circumference and waist-hip ratio: Report of a WHO expert consultation: WHO; 2011c. http://apps.who.int/iris/ bitstream/10665/44583/1/9789241501491_eng.pdf. Accessed 17 Oct 2017

23. United Nations Development Programme (UNDP). Technical notes in Human Development Report 2016. 2016. http://www.hdr.undp.org/sites/ default/files/hdr2016_technical_notes.pdf. Accessed 5 Dec 2017.

24. Oxford poverty and human development initiative (OPHI). OPHI Country Briefing 2017: Nepal. University of Oxford 2017. www.ophi.org.uk/ multidimensional-poverty-index/mpi-country-briefing/. Accessed 27 Oct 2017.

25. Florkowski C. HbA1c as a diagnostic test for diabetes mellitus - reviewing the evidence. Clin Biochem Rev. 2013;34:75-83.

26. Bhandari GP, Angdembe MR, Dhimal M, Neupane S, Bhusal C. State of noncommunicable diseases in Nepal. BMC Public Health. 2014;14:23.

27. Aryal N, Weatherall M, Bhatta YKD, Mann S. Lipid profiles, glycated hemoglobin, and diabetes in people living at high altitude in Nepal. Int J Environ Res Public Health. 2017;14:1041.

28. Riyaz MSU, Rather MK, Koul PA. Diabetes in immigrant Tibetan Muslims in Kashmir, North India. J Immigr Minority Heath. 2018;20:410-5.

29. Zheng X, Yao DK, Zhuo-Ma CR, Tang J, Wang TR, Zhang HH, et al. Prevalence, self-awareness, treatment and control of hypertension in Lhasa, Tibet. Clin Exp Hypertens. 2012;34:328-33.

30. Okumiya $K$, Sakamoto $R$, Ishimoto $Y$, Kimura $Y$, Fukutomi E, Ishikawa $M$, et al. Glucose intolerance associated with hypoxia in people living at high altitudes in Tibetan highland. BMJ Open. 2016;6:e009728.

31. Papanas N, Steiropoulos P, Nena E, Tzouvelekis A, Maltezos E, Trakada G, et al. $\mathrm{HbA1c}$ is associated with severity of obstructive sleep apnea hypopnea syndrome in nondiabetic men. Vasc Health Risk Manag. 2009;5:751-6.

32. Hui $P$, Zhao $L$, Xie $Y$, Wei $X, M a ~ W$, Wang J, et al. Nocturnal hypoxemia causes hyperglycemia in patients with obstructive sleep apnea and type 2 diabetes mellitus. Am J Med Sci. 2016:351:160-8.

33. de Rekeneire N, Peila R, Ding J, Colbert LH, Visser M, Shorr Rl, et al. Diabetes, hyperglycemia, and inflammation in older individuals: the health, aging and body composition study. Diabetes Care. 2006;29:1902-8.

34. Reuter S, Gupta SC, Chaturvedi MM, Aggarwal BB. Oxidative stress, inflammation, and cancer: how are they linked? Free Radic Biol Med. 2010:49:1603-16.

35. Netzer N, Gatterer H, Faulhaber M, Burtscher M, Pramsohler S, Pesta D. Hypoxia, oxidative stress and fat. Biomolecules. 2015:5:1143-50.

36. Beall CM. Oxygen saturation increases during childhood and decreases during adulthood among high altitude native Tibetans residing at 3800 4200 m. High Alt Med Biol. 2000;1:25-32.

37. Dubowitz N, Xue W, Long Q, Ownby JG, Olson DE, Barb D, et al. Aging is associated with increased $\mathrm{HbA} 1 \mathrm{c}$ levels, independently of glucose levels and insulin resistance, and also with decreased $\mathrm{HbA1c}$ diagnostic specificity. Diabet Med. 2014;31:927-35. 
38. Beall CM. Andean, tibetan, and ethiopian patterns of adaptation to highaltitude hypoxia. Integr Comp Biol. 2006;46:18-24.

39. Weitz CA, Garruto RM. A comparative analysis of arterial oxygen saturation among Tibetans and Han born and raised at high altitude. High Alt Med Biol. 2007;8:13-26.

40. Motoi M, Nishimura T, Egashira Y, Kishida F, Watanuku S. Relationship between mitochondrial haplogroup and physiological responses to hypobaric hypoxia. J Physiol Anthropol. 2016;35:12.

41. Yasukochi Y, Nishimura T, Motoi M, Watanuki S. Association of EGLN1 genetic polymorphisms with $\mathrm{SpO}_{2}$ responses to acute hypobaric hypoxia in a Japanese cohort. J Physiol Anthropol. 2018;37:9.

- fast, convenient online submission

- thorough peer review by experienced researchers in your field

- rapid publication on acceptance

- support for research data, including large and complex data types

- gold Open Access which fosters wider collaboration and increased citations

- maximum visibility for your research: over $100 \mathrm{M}$ website views per year

At BMC, research is always in progress.

Learn more biomedcentral.com/submissions 